\title{
A Modified Stylus for Selective Brush Plating
}

\author{
Gajanam M. Ganu and Subrato Mahapatra \\ Advanced Centre for Research in Electronics, Indian Institute of Technology, \\ Bombay 400076, India
}

\begin{abstract}
The modified stylus presented consists of a half cell made from a glass tube. The design has two major benefits: the glass tube forms a reservoir which allows for continuous plating without the need to replenish the electrolyte, and the tip of the stylus can be tapered to a fine straight or curved point, allowing plating of intricate work. If required, a wide-bore stylus is also effective.
\end{abstract}

Selective brush plating is used in preference to bath plating only when there is some special advantage in terms of quality, time, convenience or cost (1), although these restrictions still allow for numerous applications $(1,2)$.

Since time is usually the main cost determining factor, in a conventional brush-plating stylus (see Figure 1 and references 1-4 for a description) the loss in time incurred in replenishing the electrolyte, or drying of the stylus tip, constitutes a disadvantage. Other problems include: variation in the current with depletion of the electrolyte; spillage of electrolyte; and the fact that further polishing of the plated surface may be required.

The modified stylus (Figure 2) overcomes these problems. It is constructed from a suitable pyrex glass tube, one end of which may be tapered to a cross-section of $2 \mathrm{~mm}$ internal diameter, though this may vary to suit the application. The central portion of the tube can be blown into a bulb to act as an electrolyte reservoir; the tip is tightly sealed by plugging (from the inside) with surgical cotton wool.

The anode is a platinum wire $(2 \mathrm{~mm}$ diameter) inserted into the tube until it almost touches the cotton plug. Although anodes are conveniently made of carbon, platinum wire is used in this modified stylus because it may have a fine, or even curved, point. Fine carbon anodes are brittle and difficult to introduce into a curved tip, whereas platinum wire anodes present no difficulty. In addition, when using carbon anodes, the carbon fines tend to block the cotton plug.
As high temperatures are required for efficient plating, the reservoir is heated. To construct a heating coil, the bulb is first coated with a water-based paste of asbestos powder, magnesium oxide and sodium silicate. When this is dry, a nichrome wire in a glass wool sleeve is wound round the bulb and covered with asbestos paper.

When using the stylus, the coil is connected to a transformer and the temperature of the plating solution is raised to $70^{\circ} \mathrm{C}$ within $10-15$ minutes (ca. $30 \mathrm{~V} \mathrm{AC}$ ). At the same time, the substrate is heated by using a hot-air blower.

The electrolyte formulation used was:

$\begin{array}{lr}\mathrm{KAu}(\mathrm{CN})_{2} & 20 \mathrm{~g} / 1 \\ \text { Ammonium citrate } & 25 \mathrm{~g} / 1 \\ \text { Citric acid } & 8 \mathrm{~g} / 1 \\ \text { Sodium sulphate } & 15 \mathrm{~g} / 1 \\ \mathrm{pH} & 4-5\end{array}$

This electrolyte gives a current efficiency at $50-70^{\circ} \mathrm{C}$ of $85-90$ per cent at a current density of $1-5 \mathrm{~mA} / \mathrm{cm}^{2}$ of contact area. Current efficiencies were determined using small $(10 \times 10 \mathrm{~mm})$ weighed samples as substrates.

\section{Preparation of the Substrate}

The procedure for selective brush plating has been described by Rubinstein (5). Briefly, grease and oil are removed with a cotton pad containing an organic solvent, such as methanol or trichloroethane. Oxide film is removed by rubbing with talc. The surface is then cleaned using first 


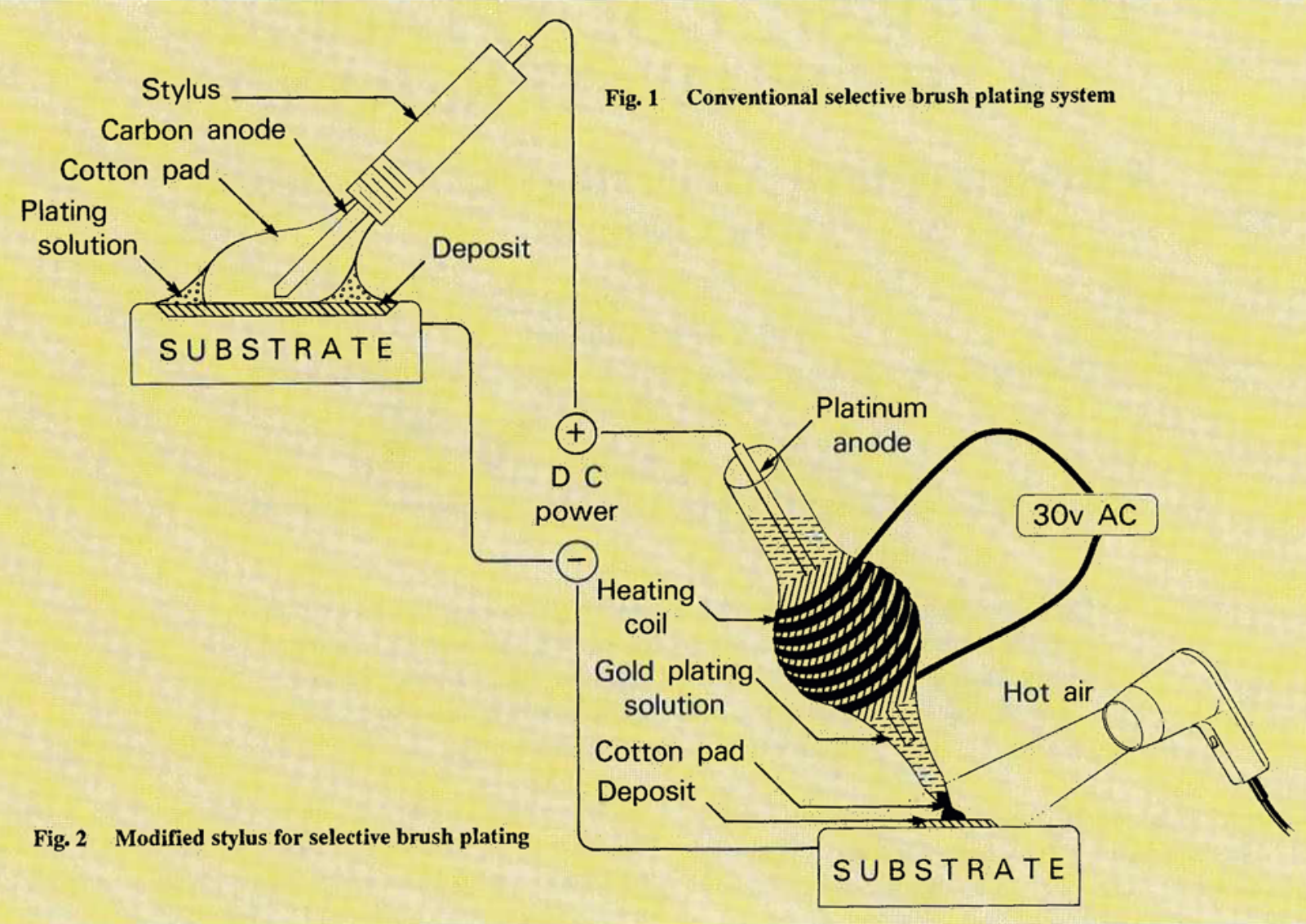

acid and then alkali. In the case of copper surfaces, we used 5 per cent hot citric acid and rinsed with distilled water. It was then cleaned with alkali and rinsed again. The cleanliness of the surface is checked by a water-break test.

Before plating, the surface must be activated. This requires different procedures depending on the nature of the substrate. Copper and brass substrates are activated using 5 per cent citric acid.

\section{Plating}

A stylus of appropriate contact area is filled with the gold plating solution, the platinum anode inserted, and the electrolyte then heated to $50^{\circ} \mathrm{C}$.

The stylus is held with a suitable protective glove, and moved continuously over the substrate without being lifted from the surface. The pressure and rate of movement determine the appearance of the deposit (semi-bright to bright). Plating is continued for the time calculated as necessary to give the required deposit thickness. The deposit is then immediately rinsed by repeated swabbing with hot water, dried with the blower, and rubbed with a soft cloth to produce a final finish. Calibration charts for controlling the plating thickness may be drawn up by plotting time against thickness for specific areas.

\section{Deposit Characteristics}

The gold films produced using the specified electrolyte in the manner described are semi-bright (canary yellow in colour) to bright (shining yellow) in appearance, depending on the pressure and rubbing action used in plating. They had a uniform and finely grained structure.

Their hardness was 120 Knoop, which was greater than that of deposits from standard cyanide baths (70 Knoop). The plating did not peel off when scratched with a pin or pulled with adhesive tape.

In samples of electronic circuitry plated using this stylus, no defects were found arising from corrosion, or loss of conductivity and signal transmission, during six months of continuous use.

\section{References}

1 M. Rubinstein, Gold Bull., 1978, 11, (1), 3-7

2 M. Rubinstein, Metal Finishing, 1981, 79, (11), 79-84

3 E. Groshart, in Metal Finishing - 50th Guide Book and Directory Issue, J. Mazia, (ed.), Metals and Plastics Publications Inc., N.J., $1982,441-449$

4 M. Rubinstein, in Gold Plating Technology, F.H. Reid and W. Goldie, (eds.), Electrochemical Publications Ltd., 1974, 181-201 5 M. Rubinstein, Metal Finishing, 1981, 79, (8), 53-58 